\title{
EDICIÓN Y DIFUSIÓN DEL LIBRO
}

\section{Book publication and distribution}

\author{
José-Antonio Millán
}

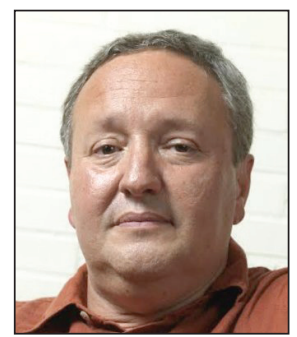

José-Antonio Millán es lingüista, doctor en literatura comparada. Como editor tradicional dirigió Taurus Ediciones. Ha ejercido la consultoría y el desarrollo de productos (cd-rom, sitios web, ebooks y aplicaciones para dispositivos móviles) en muy diversas instituciones. Ha cultivado la divulgación y la crítica de obras digitales, sobre todo en el diario El país; ha dirigido seminarios sobre aspectos de la publicación digital, y ha publicado libros y artículos que relacionan la historia de la edición con sus desarrollos actuales. Ha intervenido en el debate sobre cultura digital a través del sitio web jamillan.com, que ahora cumple veinte años.

http://orcid.org/0000-0002-3114-7676

portada@jamillan.com

\section{Resumen}

Todo el circuito del libro, tanto el tradicional como el ebook, se ha trasladado al terreno digital. Metadatos, algoritmos de recomendación y programas de limitación y control de la lectura cobran una importancia nueva. Poderosos intermediarios digitales controlan ahora la mayor parte del proceso autor-lector.

\section{Palabras clave}

Edición; Editoriales; Distribución; Promoción; Marketing; Mercado; Libros; eBooks; eReaders; Librerías; Lectores; Autores.

\section{Abstract}

The entire circuit of the book, both traditional and eBook, has moved into the digital realm. Metadata, recommendation algorithms, and programs to limit and control the reading take on a new importance. Powerful digital intermediaries now control most of the author-reader process.

\section{Keywords}

Edition; Publication; Publishers; Distribution; Promotion; Marketing; Market; Books; eBooks; eReaders; Bookshops; Bookstores; Readers; Authors.

Millán, José-Antonio (2015). “Edición y difusión del libro”. El profesional de la información, v. 24, n. 6, pp. 699-703.

\section{Introducción}

¿Qué está pasando con los libros? Que a todos los niveles, desde su autoría hasta su materialidad, pasando por el circuito autor-lector, e incluso la propia lectura, están siendo mediados digitalmente.

Un circuito que venía teniendo un funcionamiento aceptable va siendo sustituido por oligopolios que suministran a consumidores encadenados

Frente a las muchas esperanzas puestas en la nueva situación, que se suponía que democratizaría la difusión y el acceso a las obras, que abarataría costes y que favorecería en general el acceso a la cultura, la realidad ha demostrado ser diferente. Como es lógico, el libro reubicado digitalmente no ha podido quedar al margen de las tendencias a la concentración y al control características de esta fase del capitalismo. El resultado puede ser completamente disruptivo, al liquidar un circuito que venía teniendo un funcionamiento aceptable pero consensuadamente mejorable, sustituyéndolo por oligopolios que suministran a consumidores encadenados.

\section{Datos para funcionar}

La primera constatación es que los libros, tanto los de papel como los electrónicos, tienen que envolverse en una nube de datos - los metadatos - para circular. Esto significa que los editores tienen una tarea más ante ellos (antes reservada sólo a los bibliotecarios): generar para cada una de las obras que publican una descripción en el formato que las distribuidoras, de ebooks o de papel, exijan. Aparte de los datos objetivos (autor, título, ISBN...) cobran una impor- 
tancia nueva las sinopsis argumentales y las clasificaciones temáticas. Para funcionar en un mercado orientado a micronichos, éstas deben desbordar los estrechos marcos de las categorías recibidas (géneros, subgéneros), para aventurarse en las clasificaciones idiosincráticas (folk taxonomies) que ya se ven en otros ámbitos como el cinematográfico o el musical. Por supuesto, estos metadatos descriptivos de la obra tienen que estar diseñados de forma amigable para los buscadores (SEO friendly).

Para promocionar los libros se debe contar con páginas de Facebook, webs, blogs, cuentas de Twitter, de Instagram o de Pinterest

Una parte importante de la promoción y publicidad de las obras en cualquier soporte se ha vertido a la Red: los libros, las colecciones o líneas editoriales y a veces los autores deben contar con páginas de Facebook, webs, blogs, cuentas de Twitter, de Instagram o de Pinterest y tal vez booktrailers en YouTube. Además, hay que llevar acciones especiales para que páginas de recomendación de libros y blogs especializados se hagan eco de determinadas novedades. Si se comercializan en librerías virtuales, habrá también que llevar a cabo un marketing muy específico, que tiene que ver con modificaciones puntuales de precios (que, por cierto, chocan frontalmente con la política del precio fijo vigente en España). Todo ello para conseguir lo que se ha dado en llamar la descubribilidad: que los compradores potenciales se fijen en determinados libros. Esto es clave, porque una de las ventajas potenciales de la comercialización en entornos digitales es la posibilidad de llegar a nichos de lectores de todos los tamaños.

Desde hace años las empresas que acumulan información sobre ventas de sus clientes pueden recurrir a procesos típicos de los big data para conseguir recomendaciones algorítmicas. Además de la acumulación, a veces ingente, de información sobre transacciones, estos sistemas tienen la ventaja de que actúan con realidades: el voto de la compra tiene mucho más valor que la simple recomendación en el vacío de alguien a quien no le cuesta nada hacerla. Así, el "quienes compraron este libro compraron también..." se erige en uno de los procedimientos más fiables... para aquellos que saben programar adecuadamente los algoritmos, y que cuentan con una masa crítica de ventas suficiente.

\section{Una profesión progresivamente compleja}

Los últimos párrafos habrán puesto de relieve que la acción editorial exige ahora unos saberes altamente específicos: a la necesidad de construir webs y datos ricos y amigables para los buscadores se une la proliferación de las funciones del llamado community manager que pilote la acción en las redes sociales. Los antiguos ficheros de direcciones para promoción (que desde hace al menos un siglo son vitales para los editores) se han trocado en complejas bases de datos que se alimentan desde todos los puntos de la Red. Por último, la minería de los datos de ventas o del eco de las acciones en la Web o en las redes exige saberes sofisticados y una actividad lo bastante voluminosa como para que esos datos "digan" algo más o menos sensato.

El problema de esta complejificación creciente de la industria editorial es que normalmente sólo resulta abordable para grandes actores. El pequeño editor no puede gestionar por sí mismo todos los procesos típicamente editoriales (selección, control de calidad de originales y traducciones) y además los nuevos tipos de promoción y marketing en las redes. En el mejor de los casos subcontratará parte de estos procesos a empresas de servicios, que conocerán imperfectamente su catálogo, y que además se comerán parte del escaso margen de beneficio. Si el editor de papel, como es cada vez más frecuente, comercializa también la versión en ebook, se encontrará con otro flanco en el que no tiene conocimientos ni experiencia, y pronto descubrirá que muchas de sus decisiones editoriales, desde la tipografía a la maquetación, se habrán tenido que plegar a las posibilidades del nuevo medio. Para moverse en él deberá confiar de nuevo en proveedores externos, con distinto grado de fiabilidad, y sobre los que no sabrá ejercer un control de calidad.

\section{El pequeño editor no puede gestionar por sí mismo todos los procesos típica- mente editoriales}

Un área que ha experimentado una especial revolución digital es la del libro descatalogado o antiguo. Google Books, proyecto que se remonta a hace más de una década, ya ha digitalizado treinta millones de libros, pero en la actualidad se enfrenta a complejas cuestiones que afectan a obras con copyright vigente, y también a las denominadas huérfanas (aquellas de las que no se puede asegurar a ciencia cierta su estatuto de derecho de autor), todo lo cual ha situado a este ingente fondo en un impasse del que no parece poder salir. Mientras tanto, miles de instituciones (bibliotecas, universidades...) se han lanzado también a digitalizar obras de sus fondos, que en muchos casos permanecen semiocultas en sus webs.

En el nuevo circuito digital la autoría se ha desplegado: ahí están las obras colaborativas, que en ciertos casos han desplazado a productos editoriales bien asentados. El ejemplo máximo es la gigantesca Wikipedia, reflejo de cómo un software abierto y la acción de voluntarios (supervisada por grupos más reducidos y selectos de otros voluntarios) ha podido crear una obra de referencia imprescindible. O el caso de la fan fiction, ceñida a nichos de género (juvenil, ciencia ficción), pero que está creando una multitud de obras, alguna de las cuales acabará por pasar al circuito editorial normal. Aplicaciones específicas para autopublicación, como Wattpad, han hecho mucho por facilitar la publicación y la visibilidad de autores no-profesionales.

Los autores han creído ver en las plataformas digitales la posibilidad de una mejora de sus condiciones. De unas regalías normales del $10 \%$ sobre el precio de venta al público en papel se ha subido en el ebook a un $30 \%$ (eso sí, muchas veces sobre el "ingreso neto" del editor), pudiendo llegar en 
el caso de determinadas plataformas de autopublicación al 70\%. Con semejantes estímulos, no es de extrañar que los libros autopublicados hayan sido una de las categorías emergentes en la edición de ebooks.

La piratería ha sido la causa a la que se han atribuido gran parte de los males de una industria editorial en grave retroceso de ventas. Sin embargo, los datos que se ofrecen sobre la descarga no autorizada de obras (por ejemplo: que en el 2014 "el $\mathbf{8 7 \%}$ de los contenidos digitales consumidos en España fueron pirata") vienen careciendo de rigor, y provienen de metodologías poco claras. Si bien parece cierto que hay sectores a los que las descargas no autorizadas están haciendo daño, como la edición científico-técnica, tradicionalmente con obras de precios elevados, los estudios que permitirían precisar la situación global sencillamente no se han llevado a cabo. Por ejemplo, los estudios y las encuestas no deslindan la lectura de libros digitales gratuitos (de los que, por ejemplo, hay miles en el Proyecto Gutenberg y cientos en la Biblioteca Virtual Miguel de Cervantes), y la de libros obtenidos sin licencia legal. Por último, la caída de ventas de libros en papel puede deberse perfectamente a la crisis económica, sin buscar su origen en un presunto aumento de descargas no autorizadas.

La librería funciona como punto de venta directa, pero también como expositor de obras que se pueden acabar consumiendo como ebooks o adquiridas semanas después en una librería online

\section{El lector}

En el otro extremo del circuito, el lector final está sometido a un bombardeo múltiple: las librerías le reclaman con sus atestadas mesas de novedades, y le orientan con el peculiar lenguaje de estos establecimientos: los escaparates, las pilas de best-sellers, las secciones ordenadas temáticamente, y la doble articulación en la exposición: novedades/fondo. Hay que recordar que la librería hoy de hecho funciona como punto de venta directa, pero también como expositor de obras que se pueden acabar consumiendo como ebooks o adquiridas semanas después en una librería online.

Paralelamente, el comprador de libros se encontrará con referencias a obras entre sus amigos de Facebook, en la línea de Twitter, en el blog de cocina o en la web de baloncesto que frecuenta, en una publicación generalista, en papel o digital, o le llegarán por email. Esta información prenderá en su mente con distinto grado de profundidad, y en algún momento precipitará en la compra de un libro o de un ebook.

Si se ha adquirido un ebook se penetra en un terreno cualitativamente nuevo. Ya no se trata de la compra de una mercancía, sino de la prestación de un servicio, cuyas características dependen de los requisitos de la plataforma de distribución y de la de lectura (que pueden coincidir o no). El lector, por su parte, sólo habrá comprado el derecho a que una determinada pantalla (y no otra) le muestre una secuencia de letras, con frecuencia con restricciones sobre posibilidades de exportación o impresión. A cambio, habrá tenido inmediatamente acceso al libro deseado (que es algo que recalca la publicidad de los lectores de ebooks), y podrá acumular en su aparato un número desmesurado de obras, con independencia de si va o no a leerlas. Por otra parte, las obras con sistemas de protección anticopia (digital rights management, DRM) aumentan las molestias para el comprador, lo que hace que algunas editoriales comercialicen ebooks no protegidos, o dotados simplemente de un marcado social (como el nombre del comprador embebido en el archivo).

Los dispositivos lectores dedicados de libro digital (ereaders) han avanzado mucho en calidad y se han ido abaratando notablemente, pero en la actualidad compiten con otras dos plataformas de lectura: las tabletas (que pueden contener aplicaciones que emulan las prestaciones de los lectores dedicados), y los teléfonos avanzados, cuya pantalla ha ido aumentando en tamaño y definición, y que en áreas económicamente deprimidas se han convertido en un soporte normal de lectura, como ha ocurrido en África. Por otra parte, las tabletas han permitido la creación de obras bajo 
la forma de aplicaciones (es decir, programas autónomos), que generalmente explotan las capacidades multimedia de los nuevos soportes. Esto ha dado lugar a fenómenos que ya se habían vivido en la época del cd-rom (mediados de la década de los 90): títulos infantiles, o de enseñanza, u obras clásicas enriquecidas, todas ellas adornadas (venga o no a cuento) con ilustraciones clicables, animaciones o videos, que encarecen sobremanera la producción. Ha habido, claro está, obras realmente buenas, que han sacado partido de las posibilidades de los nuevos medios, pero éstas han sido realmente escasas.

\section{El libro que nos lee}

En el mundo material, con la venta del libro desaparecía todo contacto con el lector (y nunca se sabría qué ocurría después), pero el ebook está, según una expresión afortunada, leyéndonos: el propietario de la plataforma sabe a qué hora se lee, y en qué dispositivo. Sabe también cuándo se abandona la lectura, por algún tiempo o definitivamente. Puede saber qué frases se subrayan y comparten. Esta información podría ser muy útil para el editor, pero lo más normal es que quede como propiedad de la plataforma de venta/lectura, y que proporcione orientación cara a acciones futuras.

Progresivamente, estas plataformas (por ejemplo Amazon) se están convirtiendo en editores. Como cualquier vendedor, saben qué géneros y estilos son los más leídos, pero además qué longitud de obra es la más idónea (y en consecuencia se pueden encargar obras con esas características) y qué tipo de frases conquistan el corazón del lector, porque se subrayan más frecuentemente. Nook sabe, por ejemplo, que sus lectores de ciencia ficción y literatura policiaca leen más rápido que los de ficción literaria. Kobo sabe que el grueso volumen de G.R.R. Martin A dance with dragons (1.024 páginas) es leído en veinte horas. Amazon sabe que a los lectores del Quijote una de las frases que más les gusta es: "Ésa es natural condición de mujeres — dijo don Quijote-: desdeñar a quien las quiere y amar a quien las aborre-

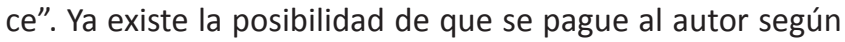
el número de páginas que se lean de su obra. Y por cierto: la venta de libros por despiece, posibilidad contemplada desde los orígenes de la edición digital, sólo está funcionando por el momento en algunos nichos concretos, como libros de texto o libro práctico. Los micropagos (a través de compañías como Dropcoin) están triunfando más en el terreno de la prensa que en el de los libros o porciones de libros, pero la situación podría cambiar.

\section{Amazon, convertida en unos grandes al- macenes virtuales, sólo obtiene el $7 \%$ de su facturación de los libros}

Las compañías que conocen el comportamiento de sus lectores pueden además permitirse acumular en los insondables almacenes de la nube millares de obras autoeditadas, a la espera de que alguna triunfe, e incluso pedir votos al público sobre proyectos de obra, para decidir cuáles verán la luz. Las grandes operadoras digitales están también copando nichos menores que tradicionalmente aumentaban la vida de la obra y el servicio al lector, como la compraventa de libros de segunda mano, o el servicio a bibliotecas. No sería de extrañar que ocuparan nuevos e incipientes nichos, como el préstamo de libros físicos entre particulares, o cualquier otra cosa nueva que surja. Porque no hay límite alguno en unas empresas que realmente sólo se dedican al libro de modo parcial: Amazon, convertida hoy en día en unos grandes almacenes virtuales, sólo obtiene el $7 \%$ de su facturación de los libros.

El lector digital de a pie puede contentarse con ser cliente de los grandes agentes, con su suministro de obras para lectores (ereaders) exclusivos, que facilitan la recomendación, la compra y la descarga, y por cierto con precios muy bajos (por la posición dominante de los proveedores sobre los editores, aunque esta situación está cambiando). O bien puede utilizar alguno de los nuevos servicios de suscripción, inevitablemente llamados "el Spotify de los libros". A este tipo de lector, las limitaciones de la licencia con que compra los libros, la imposibilidad de compartirlos, las limitaciones de uso en diferentes dispositivos, o el hecho real de que no se convierte en "propietario" de ellos, sino en "usuario", puede que no le resulten especialmente gravosos.

Pero el ebook ha dado lugar a un nuevo espécimen: el lector digital avanzado. Poco proclive a encerrarse entre los muros de

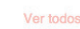

(n)


una plataforma, esta nueva especie de lector acumula en soportes locales (o en su nube privada) obras extraídas de la inmensa oferta de obras digitales, tanto ilegales como legales (de entre estas últimas, las que carezcan de protección anticopia, o DRM). Para organizar estas nuevas bibliotecas personales han surgido programas específicos, de los que el más utilizado es Calibre, que permite clasificar de forma personal libros digitales o artículos, en todos los formatos (incluido el muy utilizado pdf), y gestionar también su presencia en diferentes dispositivos.

Para el estudio y la memorización los usuarios siguen prefiriendo el papel, lo que se explica por razones espaciales y hápticas

El libro digital está conviviendo con el de papel, y parece que va a seguir siendo así. Por una parte, la lectura en pantalla favorita sigue siendo la de ficción, y muy concretamente los géneros populares (novela romántica, ciencia ficción...), mientras que para el estudio y la memorización los usuarios siguen prefiriendo el papel, lo que se explica por razones espaciales y hápticas (de relación corporal con el libro). Por otro lado, muchas veces el precio de los libros digitales no es lo suficientemente bajo para compensar las relativas mo- lestias de su uso: los editores cuyo mayor negocio está en el papel están tratando de hacer una política de precio de los ebooks que no ponga en peligro su mercado principal. Hay numerosos intentos de hibridación de las dos plataformas: por ejemplo, ebooks que se pueden comprar en una librería física (adquiriendo un soporte de cartulina con códigos a través de los que se puede acceder al ebook), o libros de papel que incluyen el derecho simultáneo a descargarse el archivo digital de la misma obra.

Y no deberíamos acabar sin una mirada a nuestro contexto inmediato. El ámbito hispanohablante es, teóricamente, un mercado único en el que podrían fluir obras en ambas direcciones, pero hace más de un siglo que muestra grandes asimetrías a favor de las obras editadas en España. El ebook no ha contribuido especialmente a crear este hipotético mercado general del libro español, entre otras razones porque, aun dentro de la misma lengua, lo más frecuente son consumos de obras locales. Por otra parte, la penetración de la lectura digital en el ámbito hispánico es aún reducida, comparada con la que tiene el mercado anglosajón.

Parece, pues, que seguiremos teniendo libros en papel y libros digitales, y es incluso posible que los primeros se beneficien de los muchos recursos para promoción y venta online que se han desarrollado para los segundos, y que de esa manera acabemos teniendo un mercado rico y con pluralidad de servicios para los lectores.

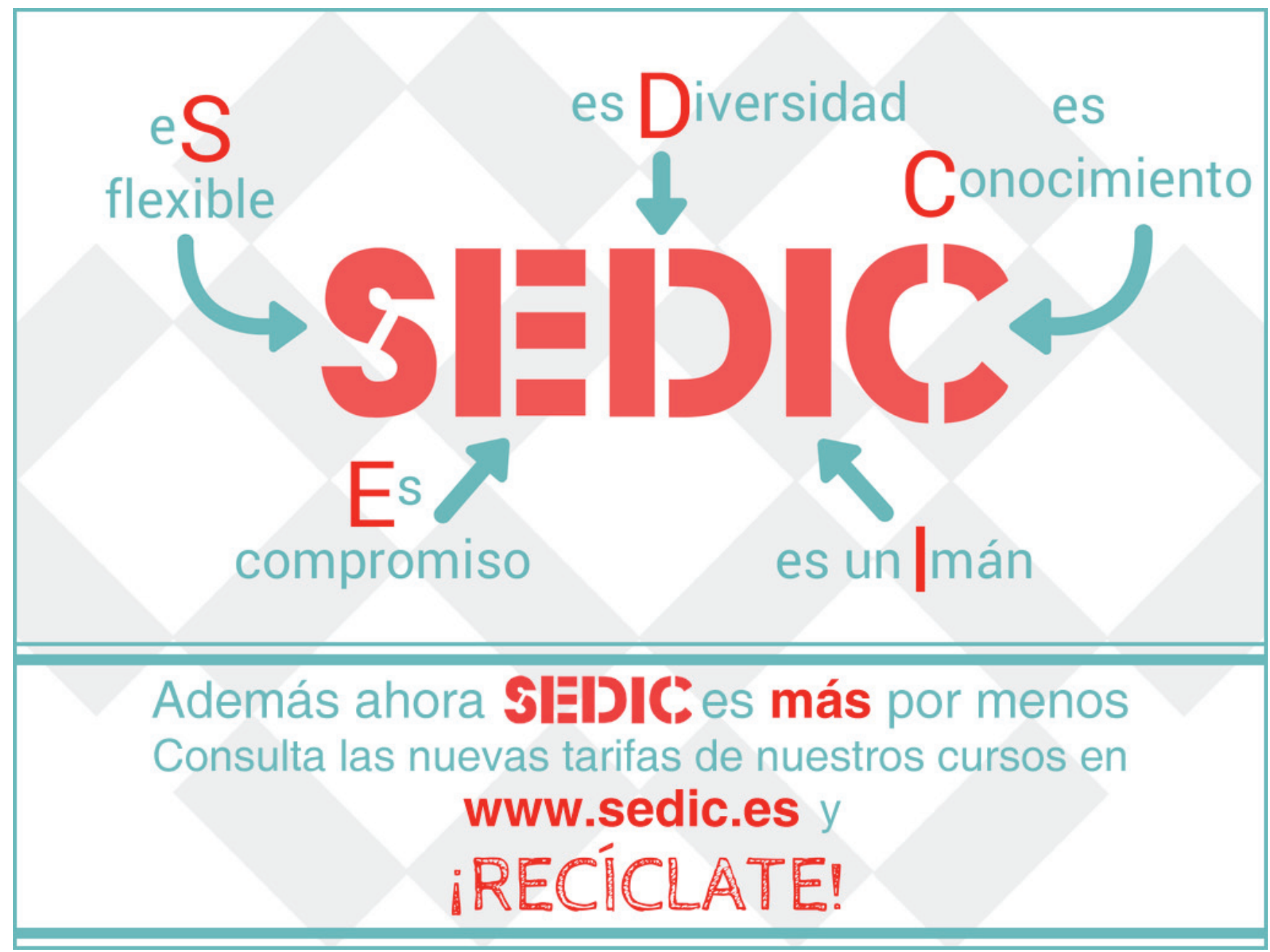

